
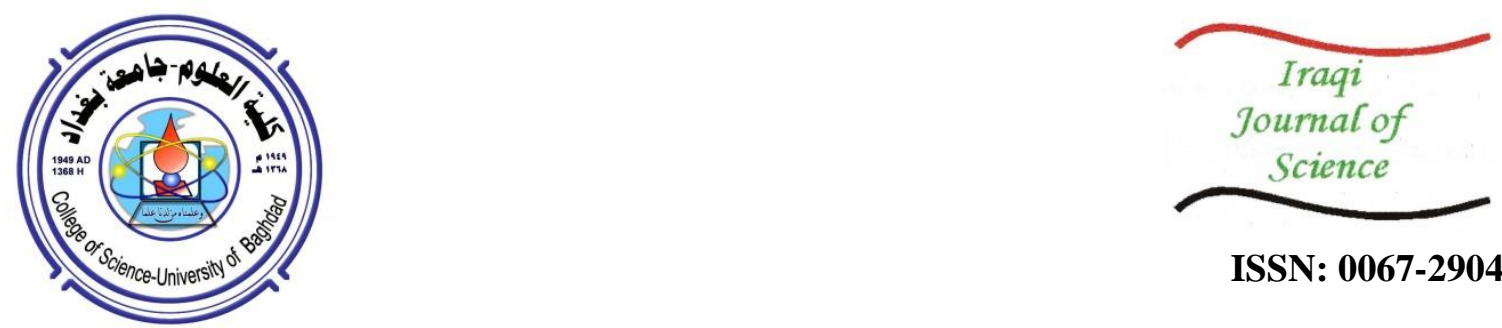

ISSN: 0067-2904

\title{
Characterization of Flexible Multi-Walled Carbon Nanotubes Network Sensor to Freon Gas Detection
}

\author{
Nisreen M. Al-Makram, Wasan R. Saleh* \\ Department of Physics, College of Science, University of Baghdad, Baghdad, Iraq
}

Received: $15 / 8 / 2020$

Accepted: 23/10/2020

\begin{abstract}
MWCNTs-OH was used to prepare a flexible gas sensor by deposition as a network on a filter cake using the method of filtration from suspension (FFS). The morphological and structural properties of the MWCNTs network were characterized before and after exposure to Freon gas using FTIR spectra and X-ray diffractometer, which confirmed that the characteristics of the sensor did not change after exposure to the gas. The sensor was exposed to a pure Freon134a gas as well as to a mixture of Freon gas and air with different ratios at room temperature. The experiments showed that the sensor works at room temperature and the sensitivity values increased with increasing operating temperature, to be $58 \%$ until $150{ }^{\circ} \mathrm{C}$. The fabricated flexible sensor has good response and recovery times at low gas concentrations of $1.3,2$, and $2.7 \mathrm{ppm}$.
\end{abstract}

Keywords: Gas sensor, Freon gas, response time, recovery time, Multi-wall carbon nanotubes, sensitivity.

\section{توصيف مستشعر شبكة الأنابيب النانوبة الكربونية المرن متعدد الجدلان لغاز الفريون}

\section{Introduction}

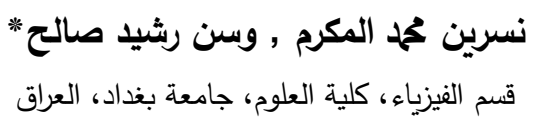

Gas sensors are chemical sensors that have a major importance. The chemical sensor involves a transducer and an active layer for converting the chemical information into electronic signals, such as frequency change, voltage change, or current change [1]. Sensors which are based on carbon nanotubes (CNTs) have been recently studied because of their excellent mechanical, electrical, and 
sensing properties. CNTs can adsorb a large number of gases, due to the large surface area, which makes them a possible competent of gas sensors, with very high sensitivity and low response time [2]. The air around us contains different types and quantities of gases, which could be hazardous to human health. It is very important to detect these gases since they exist in environments that involve humans, plants, and animals as main inhabitants, whose safety is considered a priority [3]. Classical methods used to detect air gases, which produce audio alarms to notify when there is a harmful or poisonous gas leakage, are not very dependable because they need to obtain accurate real-time measurements of the concentration of the target gas. However, various gas sensor technologies have been used for various gas detection applications [4]. Freon is the trade name for a certain class of organic chemicals called chlorofluorocarbons (CFCs), hydrochlorofluorocarbons (HCFs), and some identical compounds. Freon gas often contains hydrogen, bromine, chlorine, fluorine, and carbon [5]. It is nonflammable and, although it is often odorless, some types have an odor like ether. Freon is characterized by its gaseous condition at room temperature, but can be liquidized by pressure or cooling. It is four times heavier than air and can be discharged directly into the ground if any leakage occurs in the vessel [6]. All the carbon compounds containing hydrogen, chlorine, and fluorine are arranged as in Figure-1.

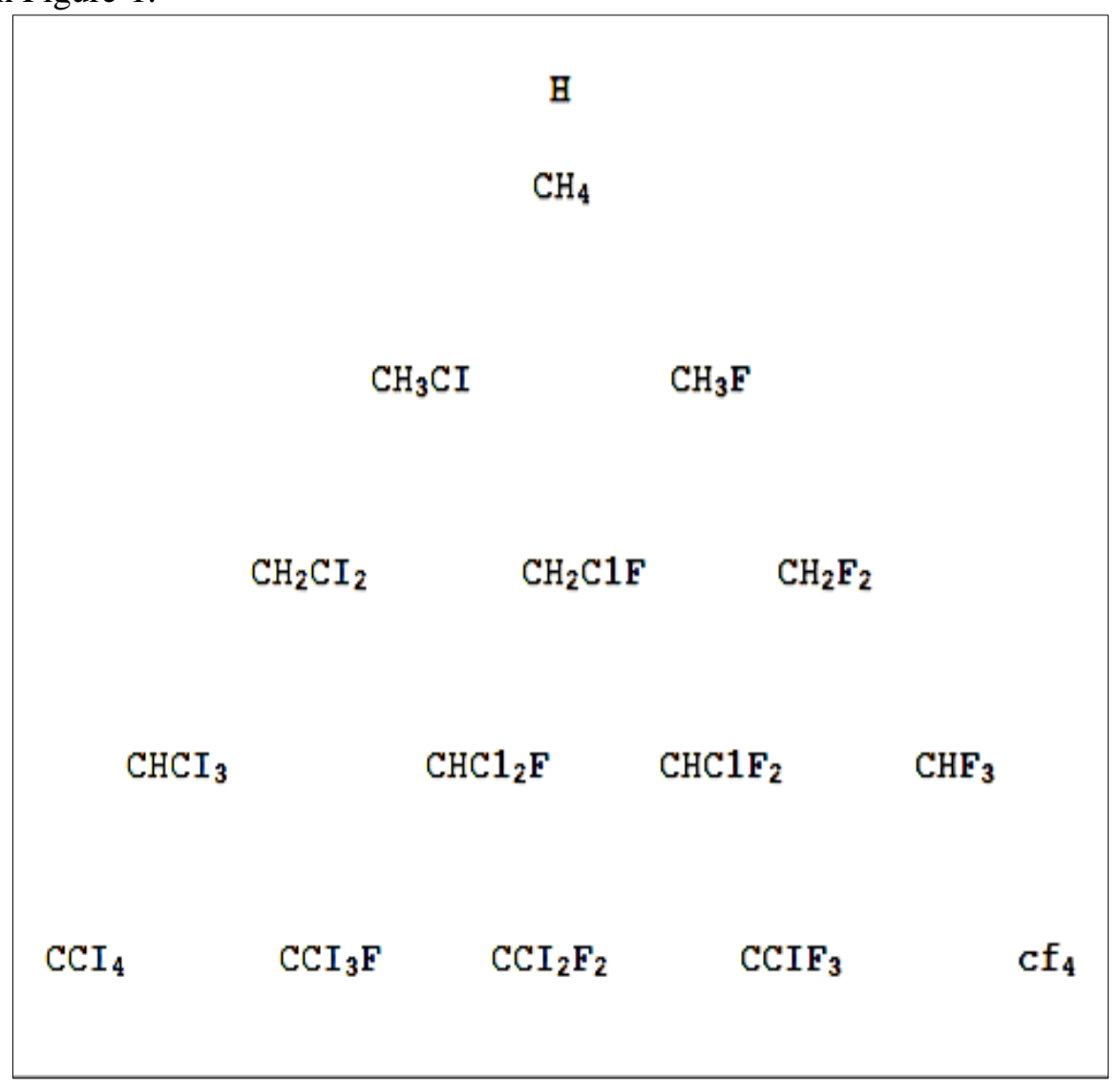

Figure 1- Methane family of refrigerants [7]

There are many different types of Freon, which are Freon R134A (HFC), Freon R22 (HCFC), Freon R410A (HFC), and Freon R11 $\left(\mathrm{CCl}_{3} \mathrm{~F}\right)$ [7]. The chemicals that contain chlorine in their components contribute to large damages to the ozone layer and, therefore, can cause its depletion. Lately, it was observed that the high concentration of dichloromethane in the atmosphere is depleting the ozone layer and is increasing very dramatically. If this increase continues, even only slightly, it will cause a delay in the recovery of the ozone layer [8]. Studies on the risks of Freon gas on the human body resulted in the conclusion that exposure to chlorofluorocarbons (CFCs) causes heart problems, such as irregularity of the beat rhythm. Despite the reports that Freon can raise levels of blood cholesterol and beta-2 microglobulin in urine, its role in high blood pressure and coronary heart disease is not clear till now [9]. 


\section{Experiment work}

In this work, a flexible MWCNTs-OH network $\left(2 \times 1 \mathrm{~cm}^{2}\right.$ dimensions) was prepared by adding $10 \mathrm{ml}$ of dimethlformamide (DMF) to $25 \mathrm{mg}$ of MWCNTs-OH, followed by sonication for $5 \mathrm{~min}$ by an ultrasonic device (solution1). At the same time, mixing $100 \mathrm{mg}$ of paraquinine (BQ) with $15 \mathrm{ml}$ of DMF and sonication for 2 min produced solution2. Then, solution1 was added to solution 2 with sonication for $5 \mathrm{~min}$. The final mixture was filtered off using a Millipore filtration system by applying the filtration from suspension (FFS) method (Figure- 2) and dried out to obtain the MWCNTs-OH network. Figure-3 demonstrates the Freon gas sensor testing system . This system consists of vacuum chamber, thermocouple with a digital thermometer, variable resistance with hot plate, rotary pump with vacuum gage, digital multimeter, Freon gas, and atmospheric air.

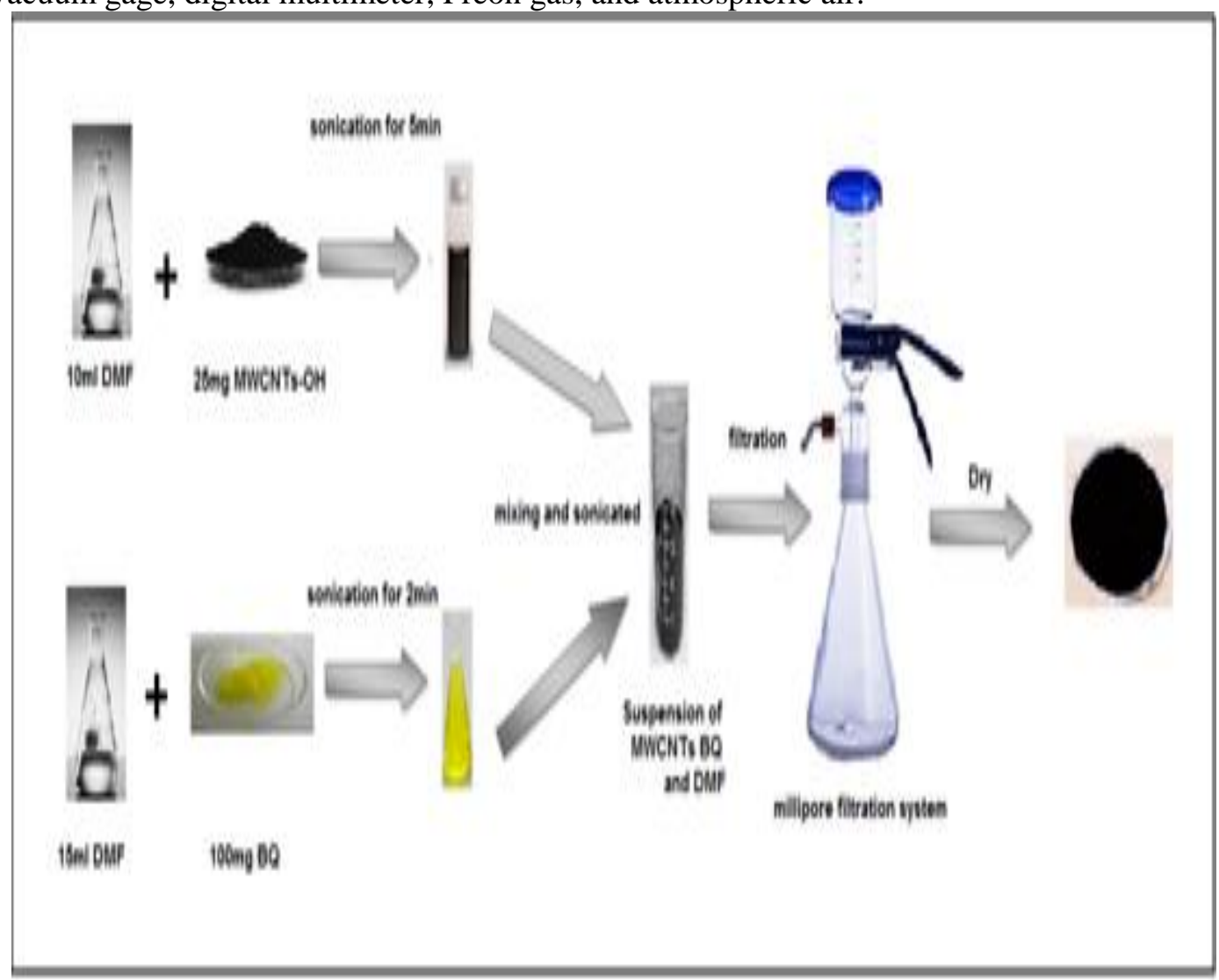

Figure 2-Schematic diagram of the FFS method used to prepare flexible MWCNTs-OH networks using a Millipore filtration system. 


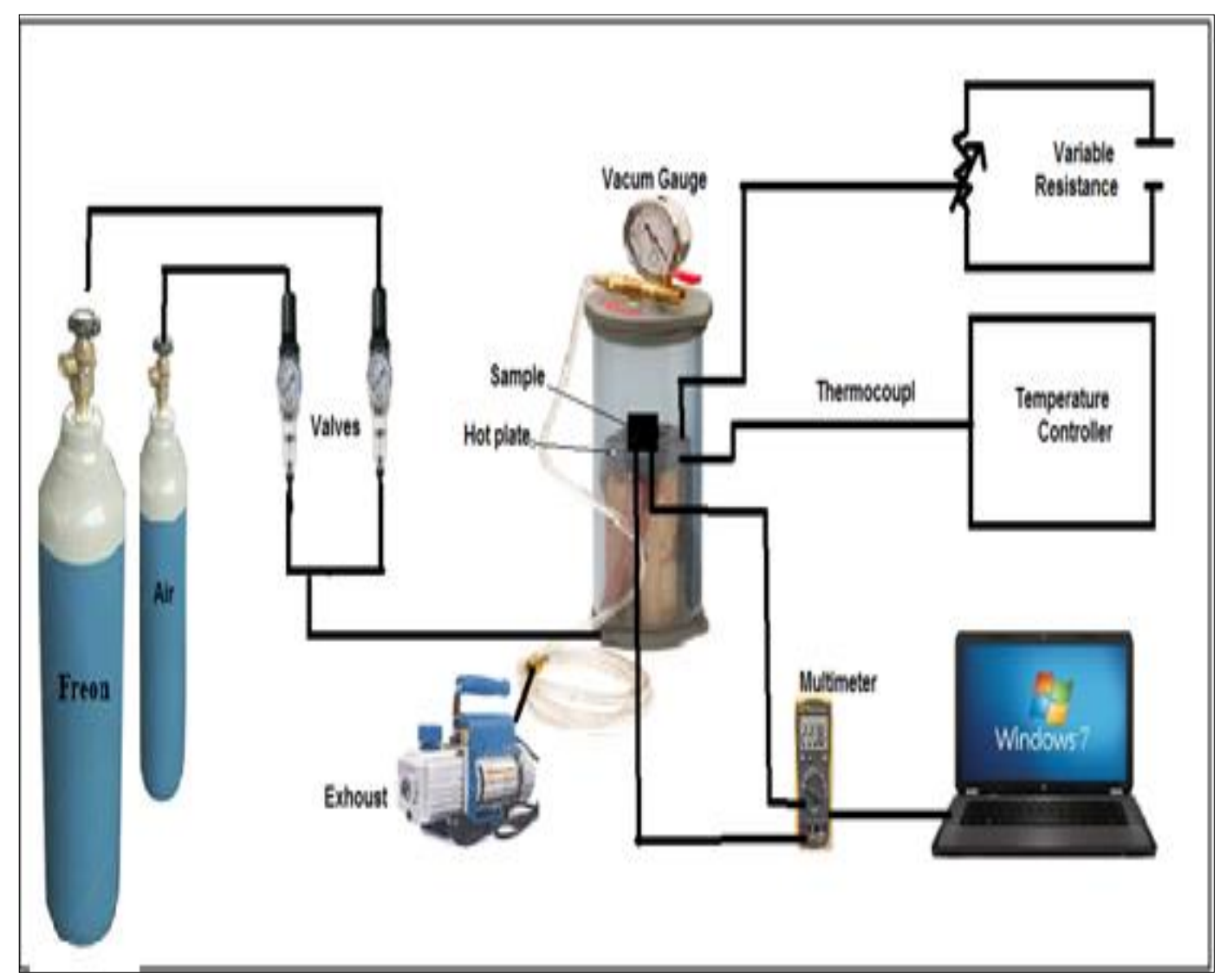

Figure 3- Schematic diagram for the Freon gas sensor testing system.

\section{Results and discussion}

This section includes the results of the experimental measurements of the prepared flexible MWCNTs network, based on the characterization of optical, morphological, and structural properties using FTIR, AFM, and XRD techniques, respectively.

Fourier transform infrared (FTIR) spectra were studied in the range of 400 to $4000 \mathrm{~cm}^{-1}$ for the MWCNTs-OH network before and after exposure to Freon gas. Figure-4a shows the FTIR spectra for MWCNTs-OH before and after exposure to Freon gas. For MWCNTs-OH, the peaks are observed at 3438 and $3465 \mathrm{~cm}^{-1}$ of the $\mathrm{O}-\mathrm{H}$ stretching band [10]. The peaks appearing in the range of 2916-2958 [11], 916, and $636 \mathrm{~cm}^{-1}$ are attributed to the $\mathrm{C}-\mathrm{H}$ stretch [10]. Moreover, the peak at $1753 \mathrm{~cm}^{-1}$ confirms the presence of the $\mathrm{C}=\mathrm{O}$ Stretch [11]. After exposing the network to Freon gas for $3 \mathrm{~min}$, the same peaks appeared, as shown in Figure-4b. These results are in a good agreement with XRD results which suggested the existence of a hexagonal structure, except the addition of a peak at $1218 \mathrm{~cm}^{-1}$ which corresponds to $\mathrm{C}=\mathrm{F}$ stretching. These results are consistent with the values reported in the literature [12]. 

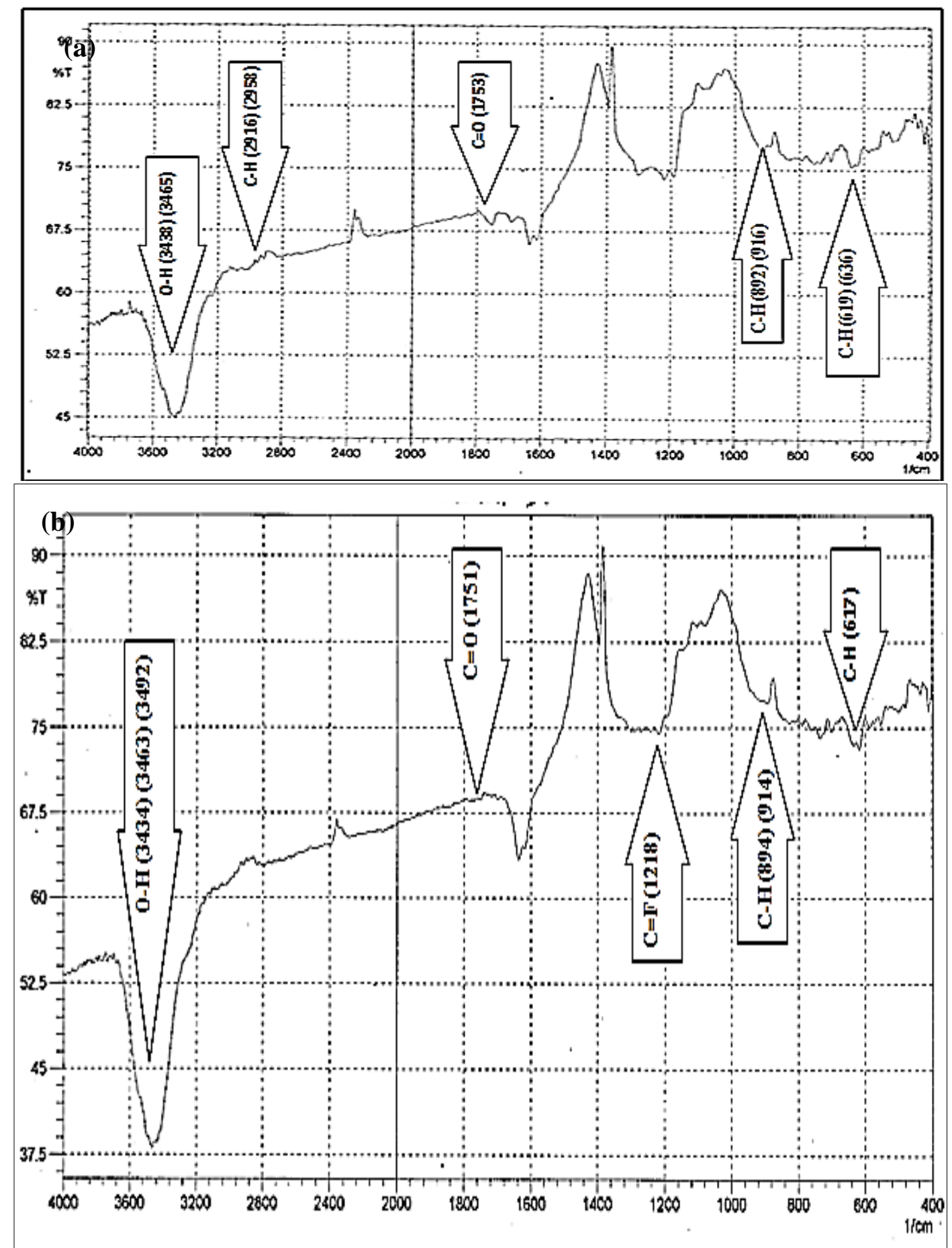

Figure 4- FTIR spectra for (a) pure F-MWCNTs network, (b) F-MWCNTs exposed to Freon gas for 3 min.

Atomic force microscope (AFM) analysis was carried out using AFM AA3000 from Angstrom advanced Inc. Figure-5 shows the 2D and 3D AFM images of the surface morphology of the flexible MWCNTs network. The images revealed that the networks have a good uniform with an average roughness $(\mathrm{Sa})$ of $15.8 \mathrm{~nm}$, indicating that the film has a good dispersive roughness. Also, the root means square roughness $(\mathrm{Sq})$ was $18.3 \mathrm{~nm}$ and the ten-point height $(\mathrm{Sz})$ value was $63.3 \mathrm{~nm}$. The granularity distribution analysis reflects that the distribution of the grain size is almost in a Gaussian shape, with a range of 500-100 nm. 


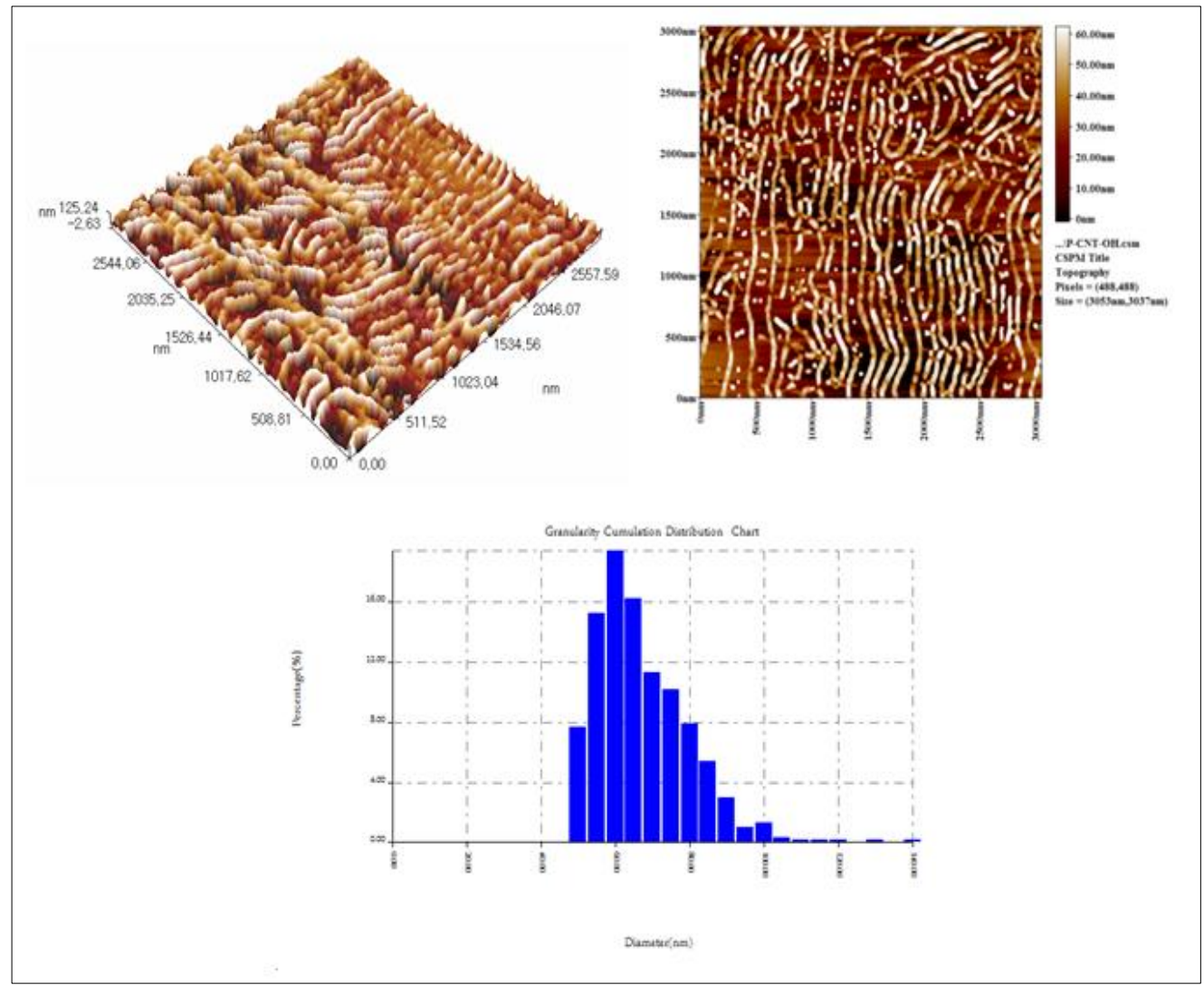

Figure 5-2D and 3D AFM images and granularity distribution of the MWCNTs-OH network.

The structural properties of the prepared network were characterized using X-ray diffractometer (Lab XRD-6000). Figure-6 shows the X-ray diffraction patterns of the MWCNT $_{\mathrm{s}}$-OH network before and after exposure to Freon gas of $40 \mathrm{mbar}$ pressure for $3 \mathrm{~min}$. There is a sharp and strong peak at the angle $2 \theta=26.400^{\circ}$ that belongs to the (002) plane, which implies a crystalline structure in the hexagonal phase. It is obvious that there is a match at the peak, which may be attributed to the nature of Freon as a reducing gas which may cause very little change in the crystal. These results are in agreement with those previously reported [13 - 16]. Table-1 summarizes the XRD patterns for the MWCNTs-OH network before and after exposure to Freon gas.

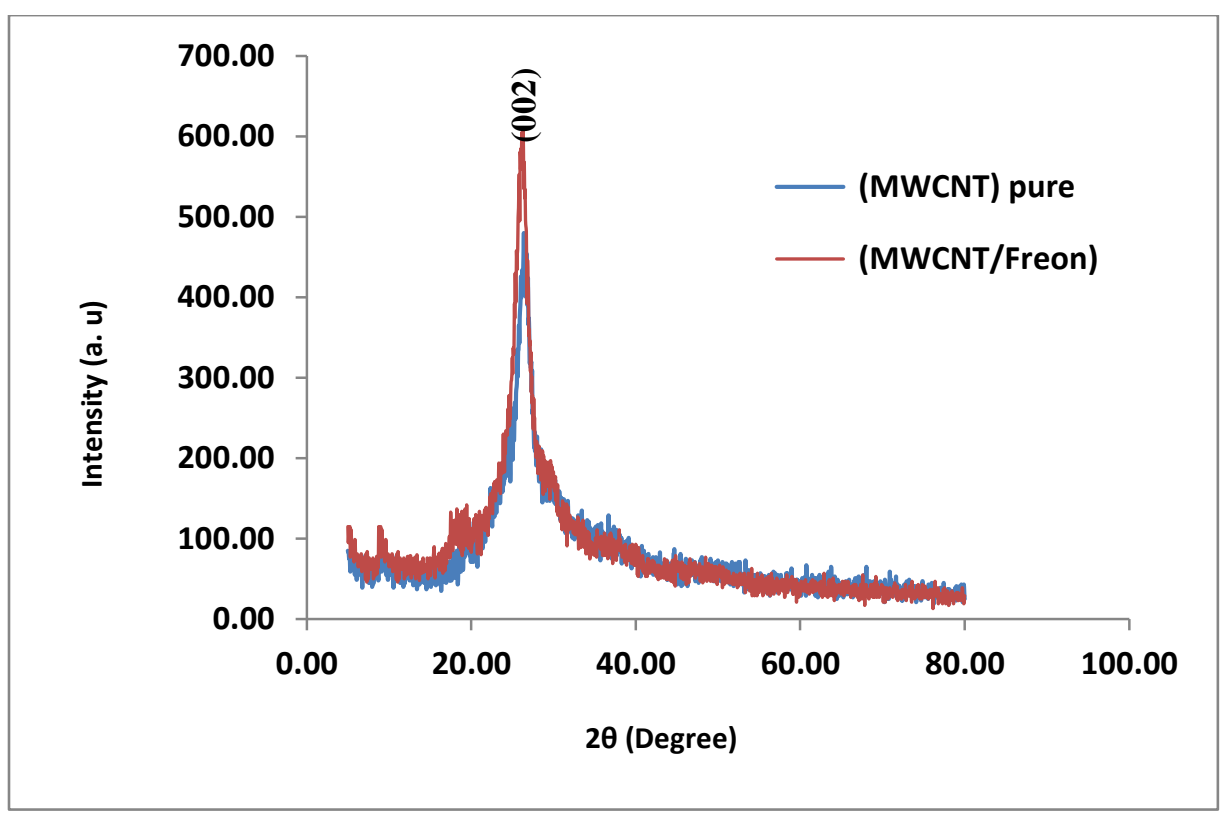

Figure 6-XRD patterns of F-MWCNTs network before and after exposure to Freon gas. 
Table1- XRD patterns of the MWCNTs -OH network before and after exposure to Freon.

\begin{tabular}{|c|c|c|}
\hline Sample(nm) & MWCNTs-OH & Freon//MWCNTs-OH \\
\hline $2 \theta$ (Deg.) & 26.4000 & 26.3000 \\
\hline FWHM (Deg.) & 1.9978 & 1.8989 \\
\hline $\mathrm{d}_{\text {hkl }}$ Exp. $(\AA)$ & 3.3733 & 3.3859 \\
\hline $\mathrm{d}_{\text {hkl }}$ Std. $(\AA)$ & 3.3540 & 3.3540 \\
\hline hkl & 002 & 002 \\
\hline JCPDC card No. & $96-901-2231$ & $96-901-2231$ \\
\hline
\end{tabular}

Sensor characterization was carried out using a home-made system, described in Figure-3, and calculated using the common sensor sensitivity $S$ given by equation $(1)[17,18]$ :

$$
S \%=\frac{(\text { Rgas }- \text { Rair })}{\text { Rair }} \times 100 \%
$$

where $R_{\text {gas }}$ is the sensor resistances upon exposure to Freon gas and $R_{\text {air }}$ is the resistance in air at certain concentrations. Figure-7 shows the sensor's response to exposure to Freon gas at concentrations of 26, 52, and $93 \mathrm{ppm}$ as well as to the mixture of Freon gas with air.

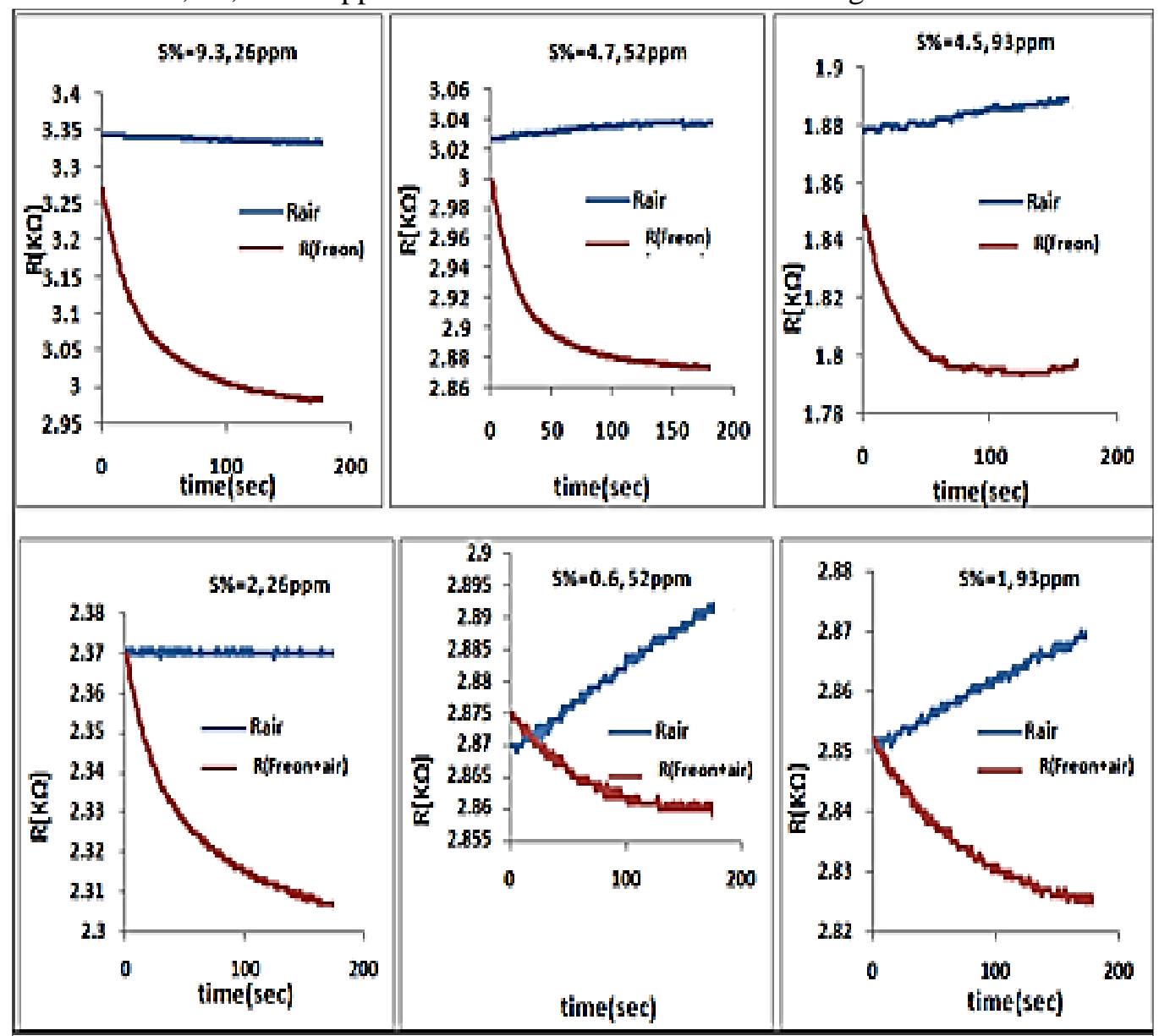

Figure 7-The resistance of the MWCNTs-OH network at various gas concentrations $(26,52,93 \mathrm{ppm})$ as a function of time after multiple exposures to Freon gas and the mixture of Freon gas and air at room temperature.

The resistance of the sensor was increased after exposure to air by a small amount, while when the sensor is exposed to a mixture of Freon gas and air, the resistance was decreased, which means increasing the conductivity of the sensor. This result proves that the MWCNTs-OH has a p-type semiconductor behavior. These results coincide with earlier results [17], indicating that the network has its own large number of free carriers (holes). When exposed to Freon gas, which is a reducing gas, 
it will attract electrons, which leads to an increase in the concentration of free carriers. Hence, the sensor resistance decreases and conductivity increases for the mixture of Freon gas with air in a ratio of 1:1. Also, the figure reveals that the resistance decreases with increasing gas concentration. When the network is exposed to pure gas with different concentrations, the sensitivity is high, while for a mixture of air and gas of the same concentrations, the sensitivity value decreases. The resistance of the sensor changes in both cases in the same amount when exposed to pure gas and when exposed to a mixture of air and gas.

Figure-8 shows the sensor's response to a mixture of different proportions of Freon gas and air for $3 \mathrm{~min}$ at room temperature. Table-2 summarizes the sensor's sensitivity values of the flexible MWCNTs-OH sensor to Freon gas mixed with air in different ratios. The results revealed that the sensor sensitivity is better in low concentrations, where it can sense the environment pollution with Freon gas in the same efficiency, while being not affected by the amount of ambient air.

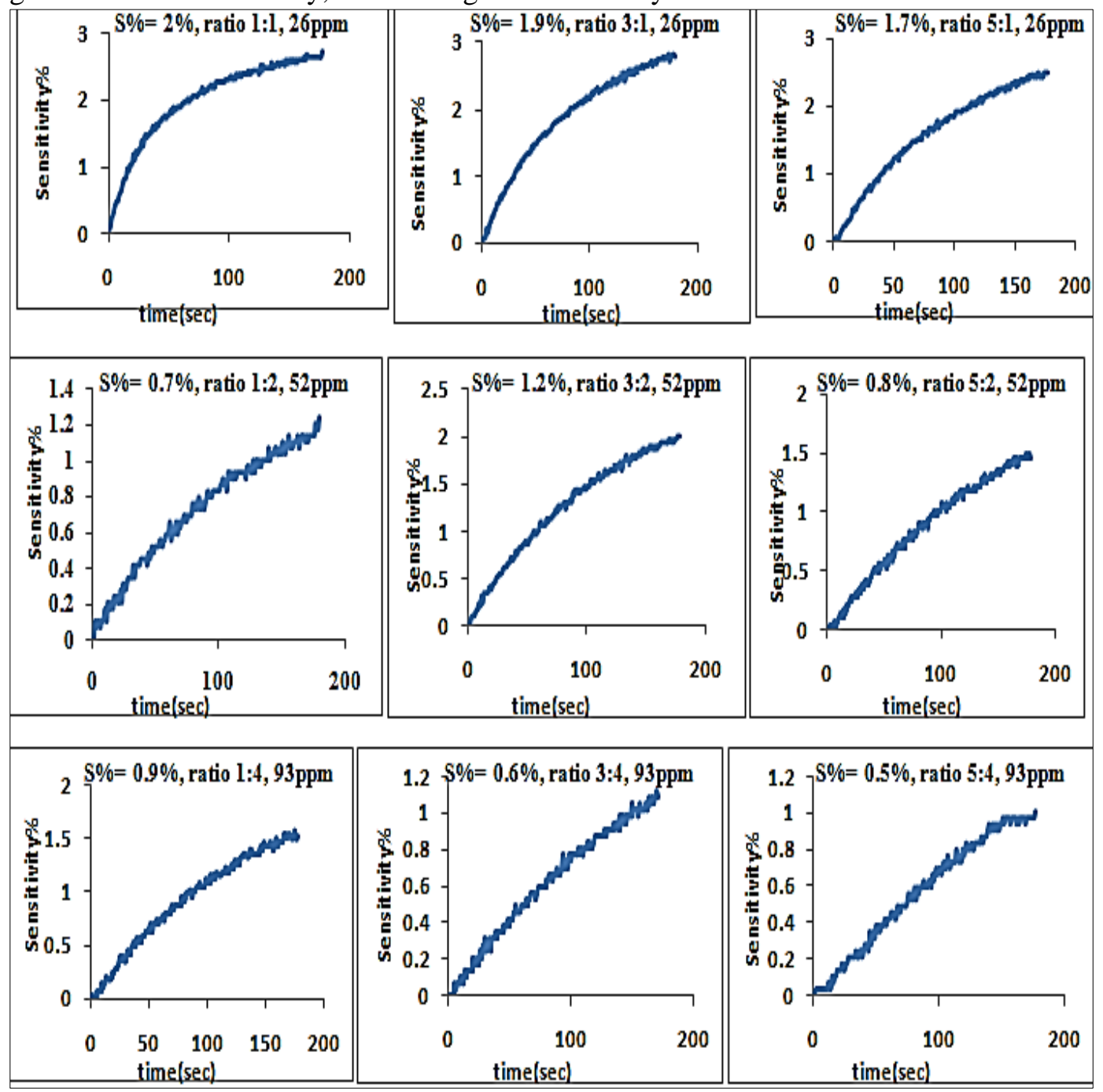

Figure 8-Sensor sensitivity as a function of time for MWCNTs-OH network with different mixing ratios of air: gas with 26ppm Freon gas at room temperature.

Table 2- The sensitivity values of the flexible MWCNTs-OH sensor to Freon gas mixed with air in different ratios.

\begin{tabular}{|c|c|c|}
\hline Gas concentration (ppm) & Mixture ratio air: gas & Sensitivity (\%) for mixture \\
\hline \multirow{3}{*}{26} & $1: 1$ & 2 \\
\cline { 2 - 3 } & $3: 1$ & 1.9 \\
\cline { 2 - 3 } & $5: 1$ & 1.7 \\
\hline \multirow{2}{*}{52} & $1: 2$ & 0.7 \\
\cline { 2 - 3 } & $3: 2$ & 1.2 \\
\hline
\end{tabular}




\begin{tabular}{|c|c|c|}
\hline & $5: 2$ & 0.8 \\
\hline \multirow{3}{*}{93} & $1: 4$ & 0.9 \\
\cline { 2 - 3 } & $3: 4$ & 0.6 \\
\cline { 2 - 3 } & $5: 4$ & 0.5 \\
\hline
\end{tabular}

Figure -9 shows the sensor sensitivity as a function of gas concentration. The sensor exposed to pure Freon gas for $3 \mathrm{~min}$ at different concentrations $(26,52,210,313,418 \mathrm{ppm})$ showed sensitivity values of $7,6.4,6.1,4.6$, and $1 \%$, respectively. The sensitivity of the sensor decreases exponentially as the gas concentration increases.

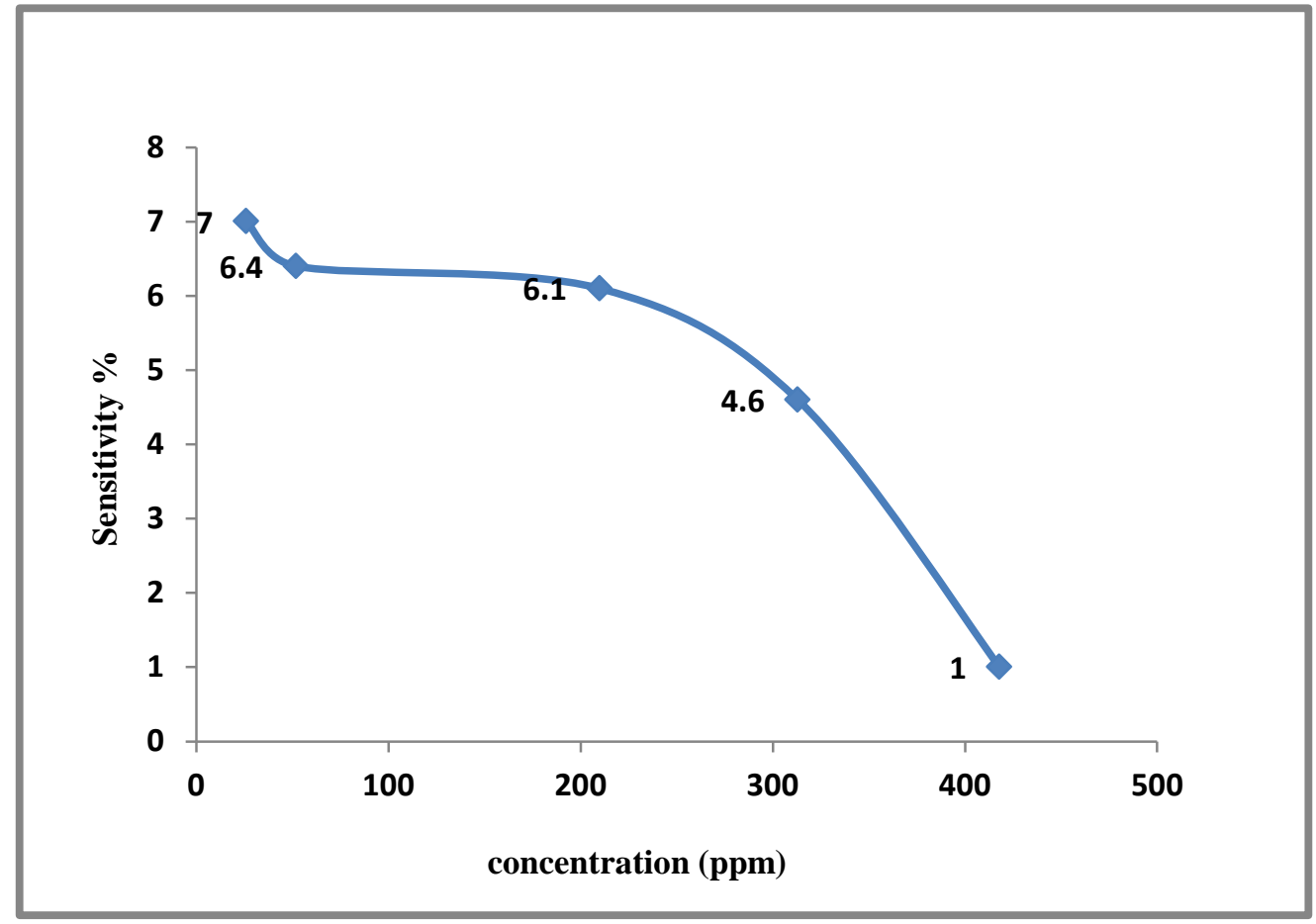

Figure 9-Sensitivity values of the sensor to pure Freon gas for MWCNTs-OH.

To estimate Freon gas concentrations at the level of one-millionth of a million as a function of operating temperature, equations (2) and (3) [18] were used.

$$
\mathrm{VP}=\mathrm{nRT}
$$

where $\mathrm{P}$ is the absolute pressure of the gas in bar units, $\mathrm{V}$ is the volume that the gas occupies, which is the chamber volume and equal to $4.3 \mathrm{~L}, \mathrm{R}$ is the universal or ideal gas constant which is equal to $8.31451 \times 10^{-2} \mathrm{~L}$. bar. $\mathrm{K}^{-1}$. $\mathrm{mol}^{-1}$, $\mathrm{T}$ is the absolute temperature of the gas in $\mathrm{K}, \mathrm{n}$ is the number of moles of gas, and the molecular weights of Freon $=133.4 \mathrm{gm} / \mathrm{mol}$.

$$
\text { Concentration }(\mathrm{ppm})=\left(\left\{\mathrm{n}(\mathrm{mol}) \times \text { molecular weights }\left(\frac{\mathrm{gm}}{\mathrm{mol}}\right)\right\} / 4.3\right) * 1000
$$

Figure- 10a shows that, at operating temperatures of RT, 50, 75, 100, and $150{ }^{\circ} \mathrm{C}$, the sensitivity was increased gradually upon the increase in temperature , recording the values of 1.8, 2.4, 4.4, 9.11, and 58) $\%$, respectively. This occurs as a result of decreasing the gas concentration, as shown in Figure$10 \mathrm{~b}$. These results proved that the fabricated flexible MWCNTs-OH sensor is functional at room temperature and its properties were improved with increasing the operating temperature till $150{ }^{\circ} \mathrm{C}$, which is in agreement with previously reported data [19]. 


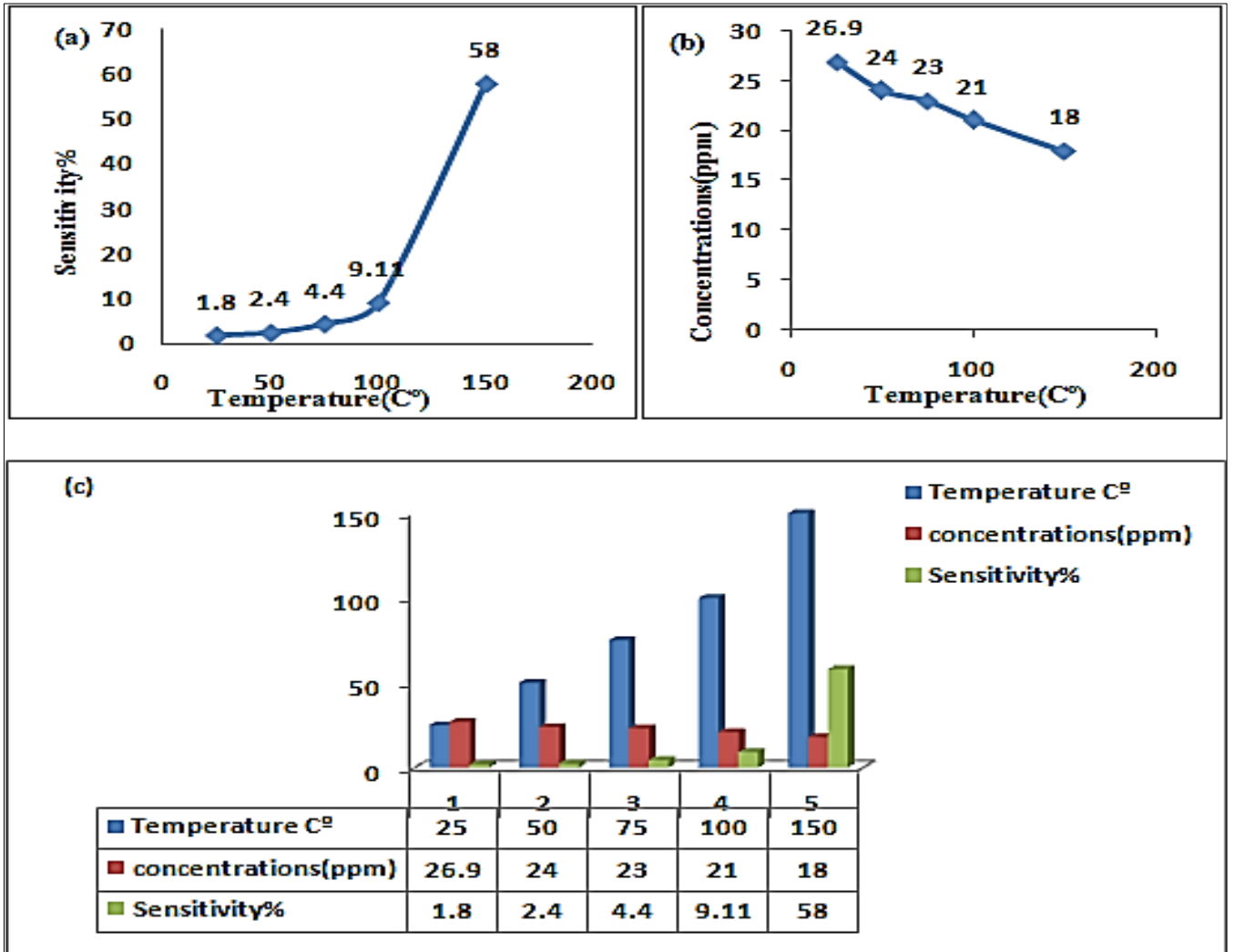

Figure 10-Sensor sensitivity and concentration as a function of temperature for MWCNTs-OH network exposed to pure Freon gas at RT, 50, 75, 100, and $150 \mathrm{C}^{\circ}$.

The response time $\left(\tau_{\text {res }}\right)$ of a gas sensor is defined as the time it takes the sensor to reach $90 \%$ of maximum or minimum value of resistance upon the introduction of the reducing or oxidizing gas. Similarly, the recovery time $\left(\tau_{\text {rec }}\right)$ is defined as the time required recovering within $10 \%$ of the original baseline when the flow of reducing or oxidizing gas is removed [20].

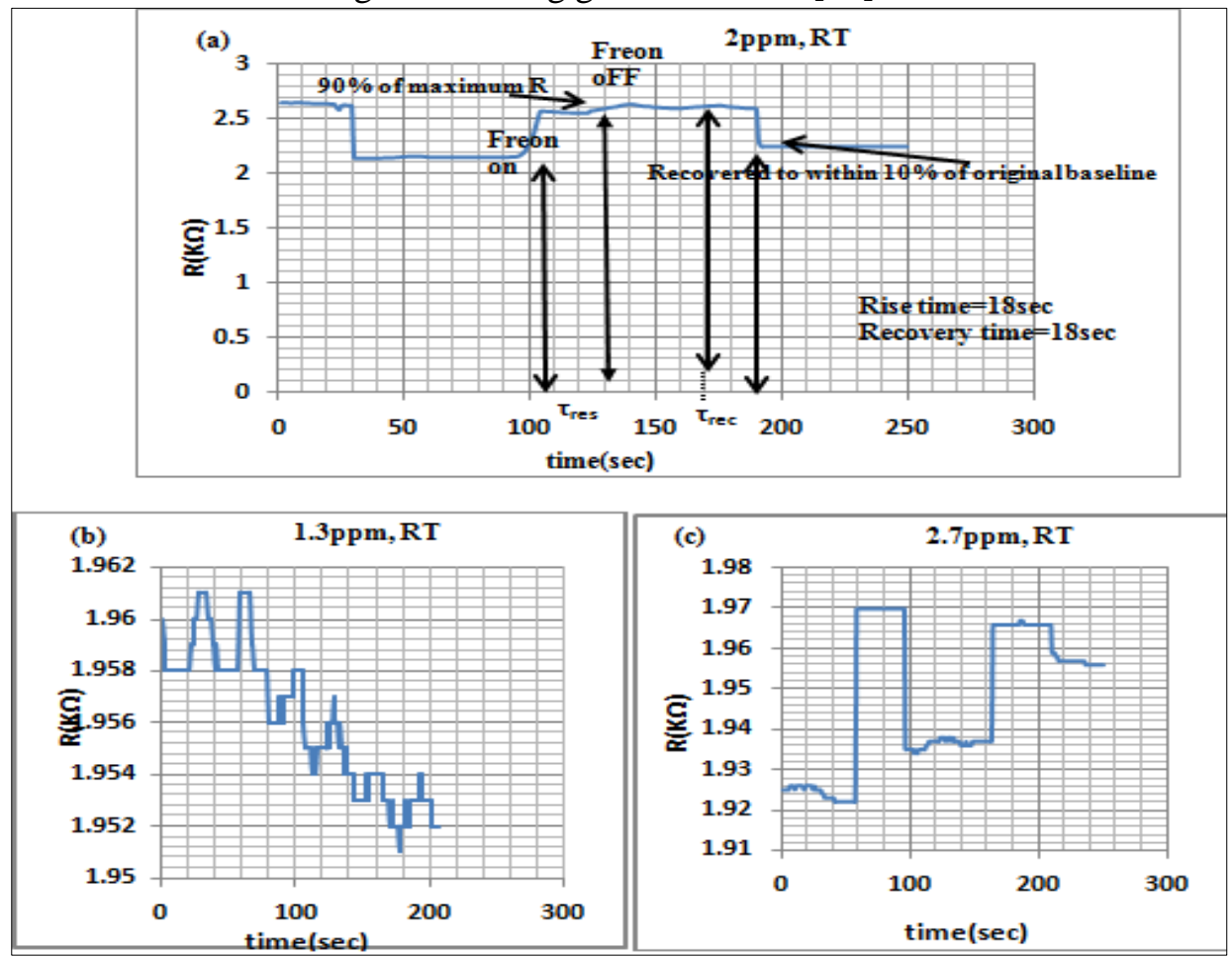

Figure 11- Response and recovery times for the flexible sensor of MWCNTs-OH network with:

A) $2 \mathrm{ppm}, \mathrm{b}) 1.3 \mathrm{ppm}, \mathrm{c}) 2.7 \mathrm{ppm}$ of Freon gas. 
Figure-11 shows the response and recovery times measured at room temperature and gas concentrations of 1.3, 2, and $2.7 \mathrm{ppm}$. The response time had values of 9,18 , and $9 \mathrm{sec}$, while the recovery time was 9,18 , and $18 \mathrm{sec}$, respectively. This reveals that whenever the concentration gets lower, the sensor response becomes faster. The response of the flexible MWCNTs $-\mathrm{OH}$ sensor is in agreement with that reported by a previous work.

\section{Conclusions}

A flexible gas sensor based on $\mathrm{MWCNT}_{\mathrm{s}}-\mathrm{OH}$ network was successfully fabricated using the FFS method. The sensor was used to detect Freon134a gas as a reduced gas. The results proved that Freon gas does not affect the structure of the prepared film, as analyzed through the X-ray diffractometer and FTIR spectra. The sensor worked at room temperature and low concentrations of Freon gas, while this sensitivity was improved with increasing the operating temperature till $150^{\circ} \mathrm{C}$. The results revealed that the sensor can sense Freon gas in the same efficiency and not affected by the amount of ambient air. The sensor also had good response and recovery times.

\section{Acknowledgement}

The authors would like to express their thanks to the associate research professor Dr. Steve Acquah from University of Massachusetts Amherst in USA for his help and useful information to prepare the network.

\section{References}

1. Mohamed, N. M., 2011. Characterization of aligned MWCNTs array as the sensing element for the ionization gas sensor. Journal of Applied Sciences, 11(7): 1243-1248.

2. Dhall, S., Jaggi, N., \& Nathawat, R., 2013. Functionalized multiwalled carbon nanotubes based hydrogen gas sensor. Sensors and Actuators A: Physical, 201: 321-327.

3. Hulanicki A., Glab S., and Ingman F., 1991. Chemical sensors: definitions and classification. Pure and Applied Chemistry, 63(9): 1247-1250.

4. L. M. Dorozhkin and I. A. Rozanov, 2001. Acoustic wave chemical sensors for gases, Journal of Analytical Chemistry, 56(5): 399-416.

5. What's That Smell? Freon", www.aetinc.biz, Retrieved 29-9-2017. Edited Francis A. Carey, Freon 'www.britannica.com, Retrieved, 29-9-2017. Edited.

6. Haresh Khemani, 2010. Properties of Refrigerant R11, or Freon 11 and Replacements, www.brighthubengineering.com, Retrieved 29-9-2017. Edited.

7. Hossaini, R., Chipperfield, M. P., Montzka, S. A., Leeson, A. A., Dhomse, S. S., \& Pyle, J. A., 2017. The increasing threat to stratospheric ozone from dichloromethane. Nature Communications, 8(1): 1-9.

8. Chaput, B., Eburdery, H., Courtade-Saïdi, M., De Bonnecaze, G., Grolleau, J. L., \& Garrido, I., 2012. Freon gas frostbite: an unusual burn evolving in two stages. Chirurgie de la Main, 31(3): 166-169.

9. Al-Tameme, H. J., Hameed, I. H., Idan, S. A., \& Hadi, M. Y., 2015. Biochemical analysis of Origanumvulgare seeds by Fourier-transform infrared (FT-IR) spectroscopy and gas chromatography-mass spectrometry (GC-MS). Journal of Pharmacognosy and Phytotherapy, 7(9): 221-237.

10. Majzlíková, P., Sedláček, J., Prášek, J., Pekárek, J., Svatoš, V., Bannov, A. G., \& Hubálek, J.,2015. Sensing properties of multiwalled carbon nanotubes grown in MW plasma torch: electronic and electrochemical behavior, gas sensing, field emission, IR absorption. Sensors, 15(2): 2644-2661.

11. Deepak, P., Sowmiya, R., Balasubramani, G., \& Perumal, P., 2017. Phytochemical profiling of Turbinariaornata and its antioxidant and antiproliferative effects. Journal of Taibah University medical sciences, 12(4): 329-337.

12. Mohamed, M. M., Fouad, S. A., Elshoky, H. A., Mohammed, G. M., \& Salaheldin, T. A., 2017. Antibacterial effect of gold nanoparticles against Corynebacterium pseudotuberculosis. International Journal of veterinary science and medicine, 5(1): 23-29.

13. Ban, Z., Barnakov, Y. A., Li, F., Golub, V. O., \& O'Connor, C. J., 2005. The synthesis of coreshell iron@ gold nanoparticles and their characterization. Journal of Materials Chemistry, 15(43): 4660-4662. 
14. Krishnamurthy, S., Esterle, A., Sharma, N. C., \& Sahi, S. V. 2014. Yucca-derived synthesis of gold nanomaterial and their catalytic potential. Nanoscale research letters, 9(1): 627.

15. Long, N. V., Thi, C. M., Nogami, M., \& Ohtaki, M., 2012. Novel issues of morphology, size, and structure of $\mathrm{Pt}$ nanoparticles in chemical engineering: surface attachment, aggregation or agglomeration, assembly, and structural changes. New Journal of Chemistry, 36(6): 1320-1334.

16. Al-Husseini, A. H., Saleh, W. R., \& Al-Sammarraie, A., 2019. A Specific $\mathrm{NH}_{3}$ Gas Sensor of a Thick MWCNTs-OH Network for Detection at Room Temperature. In Journal of Nano Research, 56: 98-108. Trans Tech Publications.

17. ]Al-Husseini, Afnan H., Wasan R. Saleh, 2019. Gas Sensor Based on Multiwall Carbon Nanotubes Network Dopped with Metallic Nanoparticles. A Thesis Submitted to the Council of the College of Science University of Baghdad.

18. Dilonardo, E., Penza, M., Alvisi, M., Rossi, R., Cassano, G., Di Franco, C., \& Cioffi, N., 2017. Gas sensing properties of MWCNT layers electrochemically decorated with $\mathrm{Au}$ and $\mathrm{Pd}$ nanoparticles. Beilstein journal of nanotechnology, 8(1): 592-603.

19. Hial, Q. G., 2011. Improvement of $\mathrm{ZnO}$ and $\mathrm{SnO}_{2}$ hydrogen gas sensors (Doctoral dissertation, Ph.D. Thesis University of Baghdad, Iraq).

20. Waleed, K., \& Asama, N. N., 2018. Fabrication of Room Temperature $\mathrm{NO}_{2}$ Gas Sensor based on Silver Nanoparticles-Decorated Carbon Nanotubes. 